\title{
Relationship between pseudoexfoliation syndrome and erectile dysfunction: a possible cause of endothelial dysfunction for development of erectile dysfunction
}

Sabite Emine Gökce ${ }^{1}$, Mehmet Ilker Gökce ${ }^{2}$

1 Department of Ophtahalmology, Kudret Eye Hospital, Turkey; ${ }^{2}$ Department of Urology, Ankara University School of Medicine, Turkey

\section{ABSTRACT}

Objectives: Pseudoexfoliation syndrome (PES) is a common age-related fibrillopathy related to accumulation of pseudoexfoliation material (PEM) in certain places in the body, especially blood vessels. Erectile dysfunction (ED) is another condition related to vascular pathology and in this study it is aimed to identify the relationship between ED and PES.

Materials and Methods: Data of 92 patients were investigated. There were 34 patients in the PES group and 58 patients in the control group. Presence of diabetes, hypertension, smoking history, BMI, and serum levels of lipids and testosterone were recorded. The groups were compared for ED rates and severity. Also logistic regression analysis was performed to identify independent risk factors for development of ED.

Results: Mean age of the population was 67.3. No significant difference was observed between the two groups regarding the presece of DM, HT, smoking, BMI and laboratory measurements. ED rate was significantly higher in the PES group (70.6\% vs 48.3\%, $\mathrm{p}=0.002)$. Also, severe ED rate was higher in the PES group ( $\mathrm{p}=0.002)$. PES was detected as an independent risk factors for the development of ED.

Conclusion: ED is a possible consequence of PES. ED rate and severity is found to be higher in the PES group and PES is detected as an independent risk factor for development of ED. Patients with PES should be informed about development of ED and further prospective trials with objective measurements of penile blood flow should be conducted to verify the erectile status and penile blood flow in PES patients.

\section{ARTICLE INFO}

Key words:

Syndrome; Erectile Dysfunction;

Exfoliation Syndrome

Int Braz J Urol. 2015; 41: 547-51

Submitted for publication:

June 04, 2014

Accepted after revision:

September 16, 2014

\section{INTRODUCTION}

Pseudoexfoliation syndrome (PES) is a common age-related fibrillopathy of unknown cause and is the most common clinical precursor of open-angle glaucoma (1). Originally, pseudoexfoliation material (PEM) accumulation was thought to be limited to the anterior segment of the eye; however, accumulation in blood vessels, heart, liver, and lung were also demonstrated in recent studies (2-4).

Accumulation of PEM in blood vessels leads to endothelial dysfunction (5). Endothelial dysfunction is currently shown to be responsible for several clinical problems related to the vascular system and one of the main consequences of endothelial dysfunction is erectile dysfunction (ED). ED is a prevalent and chronic disorder in 
men over 40 years old (6) and with increasing life expectancies, the prevalence of ED is expected to increase, particularly in men with endothelial dysfunction (7-10).

PES and ED are two conditions that affect the same age group and endothelial dysfunciton seems to be associated with both conditions. Therefore investigation of associaton of these two conditions seems to be reasonable. However, to our knowledge, there had been no studies investigating the relation of PES and ED. In this study we aimed to identify the association of PES and ED and whether PES is a risk factor for development of ED.

\section{MATERIALS AND METHODS}

Patients admitted to ophthalmology outpatient clinics between October 2012 and April 2013 were involved in the study. All patients underwent complete ocular examination and meticulous examination for presence of PEM acumulation. Male patients $\geq 65$ years of age with PES were involved in the study group (PES group) and a control group of male patients at the same age group without PES was established. Control group consisted of patients with normal anterior and posterior chamber examination, normal optic disc findings and normal visual field test. Patients with history of any pelvic surgery, use of any kind of medication for ED, having any neurological or mental problem, using antiandrogens and lacking a regular sexual partner were excluded.

PES diagnosis is based on presence of pseudoexfoliation material on pupillary area, and/ or anterior capsule of the lens, together with no abnormalities on visual field and fundus. Erectile function status was evaluated by the International Index for Erectile Functions (IIEF) and ED was classified as mild, moderate or severe based on IIEF score. The severity of ED was classified as: severe ( 5 to 7 ), moderate (8 to 11 ), mild to moderate (12 to 16 ), mild (17 to 21), and no ED (22 to 25 ). History of Diabetes Mellitus (DM), hypertension (HT) and smoking together with body mass index (BMI) were also recorded.

Medical history and physical examination were performed to exclude any neurological or genitourinary abnormality. Laboratory analysis including liver and kidney functions, serum tes- tosterone level, serum fasting glucose level, serum lipid profile including cholesterol, triglycerides, low-density lipoproteins (LDL), high-density lipoproteins (HDL) and very low-density lipoproteins (VLDL) were measured.

Sample size estimation was performed by a conventional statistical program by taking into account an effect size of 30\% difference in ED rates between the two groups and minimum number of patients needed to reject the null hypothesis was 60 (30 for each group).

\section{Statistical analysis}

Statistical analysis was done by SPSS version 15.0 programme. For detection of normal distribution of the variables, Kolmogorov-Smirnov test was used. The chi-square analysis or Fishers exact test was used to assess the significance of differences between dichomatous variables. Continuous variables were compared by Student's t test or Mann-Whitney U test. To determine indendent prognostic factors for the development of ED, logistic regression analysis was performed. $P$ value of 0.05 was accepted for statistical significance.

\section{RESULTS}

A total of 92 patients were included in the study. Mean age of the population was $67.3 \pm 8.1$. PES group consisted of 34 patients and there were 58 patients in the control group. Mean age of the PES group was $68.2 \pm 9.9$ years and mean age of the control group was $66.7 \pm 8.2(\mathrm{p}=0.345)$. DM and HT were present in 5 and 7 of the 34 patients in the PES group, and and 9 and 11 of the 58 patients in the control group. No significant difference was observed between the two groups in relation to rates of DM, HT, smoking and BMI. Similarly the groups were also similar in terms of laboratory measurements. The results are summarized in Table-1.

When the two groups were compared for presence and severity of ED, the prevalence of ED was found to be significantly higher in the PES group compared to the control group $(70.6 \%$ vs $60.3 \%, \mathrm{P}=0.002$ ). More importantly, prevalence of severe ED was significantly higher in the PES group compared to the control group (54.2\% vs $31.4 \%$, $\mathrm{p}=0.002$ ). The results are summarized in Table- 2 . 
Table 1 - Demographic characteristics and serum measurements of the patients.

\begin{tabular}{lccc}
\hline Parameters & PES Group $(\mathrm{n}=34)$ & Control Group $(\mathrm{n}=58)$ & P Value \\
\hline Age $($ mean $\pm \mathrm{SD})$ & $68.2 \pm 9.9$ & $66.7 \pm 8.2$ & 0.345 \\
Presence of $\mathrm{DM}(\%)$ & $5 / 34(14.7)$ & $9 / 58(15.5)$ & 0.258 \\
Presence of $\mathrm{HT}(\%)$ & $7 / 34(20.5)$ & $11 / 58(18.9)$ & 0.365 \\
Smoking history $(\%)$ & $17 / 34(50.0)$ & $30 / 58(51.7)$ & 0.440 \\
BMI (mean $\pm \mathrm{SD})$ & $24.7 \pm 5.1$ & $25.2 \pm 5.7$ & 0.339 \\
Serum cholesterol $(\mathrm{mg} / \mathrm{dL})$ & $185.3 \pm 18.2$ & $182.6 \pm 17.9$ & 0.463 \\
Serum triglycerides $(\mathrm{mg} / \mathrm{dL})$ & $145.4 \pm 13.8$ & $150.4 \pm 14.4$ & 0.496 \\
Serum LDL $(\mathrm{mg} / \mathrm{dL})$ & $120.3 \pm 10.7$ & $117.6 \pm 9.9$ & 0.455 \\
Serum HDL $(\mathrm{mg} / \mathrm{dL})$ & $43.3 \pm 7.1$ & $42.6 \pm 6.1$ & 0.387 \\
Serum testosterone $(\mathrm{ng} / \mathrm{mL})$ & $344.5 \pm 26.3$ & $348.8 \pm 25.9$ & 0.448 \\
\hline
\end{tabular}

Table 2 - Comparison of two groups for presence of ED and severity.

\begin{tabular}{lccc}
\hline Parameters & PES Group $(n=34)$ & Control Group $(n=58)$ & P Value \\
\hline Presence of ED (\%) & $24 / 34(70.6)$ & $28 / 58(48.3)$ & \\
Mild ED (\%) & $4 / 34(11.7)$ & $8 / 58(13.7)$ & \\
Mild to moderate ED (\%) & $3 / 34(8.8)$ & $8 / 58(13.7)$ & 0.002 \\
Moderate ED (\%) & $4 / 34(11.7)$ & $9 / 58(15.5)$ & \\
Severe ED (\%) & $13 / 34(38.2)$ & $3 / 58(5.1)$ & \\
No ED (\%) & $10 / 34(29.4)$ & $30 / 58(51.7)$ & \\
\hline
\end{tabular}

Results of logistic regression analysis revealed that presence of DM, PES , serum testosteron level, cholesterol level, fasting blood glucose levels and history of smoking were independent risk factors for the development of ED. Age and presence of HT were not found to be independent risk factors for development of ED. The results of logistic regression analysis are summarized in Table-3.

Table 3 - Results of mutivariate analysis.

\begin{tabular}{lcc}
\hline Parameters & $\mathrm{HR}(95 \% \mathrm{Cl})$ & $\mathrm{P}$ value \\
\hline Age & $1.135(0.861-1.877)$ & 0.41 \\
$\mathrm{DM}$ & $1.724(1.231-3.144)$ & 0.01 \\
$\mathrm{HT}$ & $1.101(0.782-1.653)$ & 0.47 \\
$\mathrm{PES}$ & $1.690(1.150-2.472)$ & 0.01 \\
Serum Testosteron $(\mathrm{ng} / \mathrm{mL}$ & $2.047(1.430-4.097)$ & 0.008 \\
Serum Cholesterol $(\mathrm{mg} / \mathrm{dL})$ & $1.811(1.241-2.550)$ & 0.01 \\
Serum glucose level $(\mathrm{mg} /$ & $1.644(1.130-2.138)$ & 0.01 \\
$\mathrm{dL})$ & & \\
\hline $\mathrm{DM}=$ diabetes mellitus; $\mathrm{HT}$ = hypertension; PES = Pseudoexfoliation syndrome
\end{tabular}

\section{DISCUSSION}

PES is defined as a fibrillopathy, characterized by overproduction of pseudoexfoliation material and its accumulation in ocular tissues and elsewhere. This syndrome affects about 30\% of people over the age of 60 years and it is the most common cause of open angle glaucoma (1). In electron microscopic studies its accumulation in heart, kidney, skin, lungs, liver, bladder, aorta and cerebral vasculature has been demonstrated (11, 12). This accumulation in other systemic tissues brings into mind the idea of PES as a systemic disease. Small and middle sized vessels are shown to be affected by PES (3).

ED is another conditon with underlying vascular pathology. Coordinated work-up of vascular, neuronal and psychosomatic systems is crucial for the management of erection. With increasing age among those coordinated systems, vascular system is affected more commonly, and it is the main target for urologists in the medical 
management of ED. Other clinical problems associated with endothelial dysfunction may have relationship with the development of ED. PES which was found to be associated with endothelial dysfunction may also have causative relationship with ED.

To date there are no studies investigating the possible relationship between these conditions and our data revealed that ED was present in 24 of the 34 patients with PES, which is significantly higher compared to those without PES (28 of 58 patients). Besides, in the PES group, siginificantly more patients suffered from severe ED, compared to the control group. Additionally, prevalence of ED in the PES group is striking (70.4\%). In the previous studies, even in patients with DM, ED prevelance reaches about 75\% (13-15). Therefore, results of our study reveals that PES seems to be an important vascular risk factor for the development of ED.

Moreover, in multivariate analysis, the presence of PES was shown to be an independent risk factor for the development of ED together with DM, serum cholesterol, testosteron and fasting blood glucose levels. This finding is also as important as the presence of DM and serum cholestorel levels, that are also associated with endothelial dysfunction and vascular ED. Therefore, the presence of PES seems to have its own role for development of endothelial dysfunction and this should further be evaluated in future studies either by measuring blood flow or histopathological examination of vascular wall structures.

A major drawback of our study is lacking of objective measurement of decreased blood flow to the corpus cavernosum. This may prove the possible status of erectile tissue. However, this is being studied in another on-going prospective controlled trial in our institution and nocturnal penile tumescence test and penile doppler ultrasonography are being used to evaluate the status of penile blood flow. Also, our study is a cross-sectional study, that represents the PES and ED status of the studied population. Therefore, the patients should be followed prospectively to verify the erectile function status after development of PES.

All patients in our population were naive for any medication for ED. Therefore investigation of this population for response to phosphodiesterase type $\mathrm{V}$ inhibitors should also be performed.

\section{CONCLUSION}

PES has systemic consequences related to accumulation in vessel walls. ED is a possible consequence of PES. ED rate and severity is found to be higher in the PES group and PES is detected as an independent risk factor for development of ED. Patients with PES should be informed about development of ED and may be consulted by an urologist. Further prospective trials with objective measurements of penile blood flow should be conducted to verify the erectile status and penile blood flow in PES patients.

\section{CONFLICT OF INTEREST}

None declared.

\section{REFERENCES}

1. Ritch R, Schlötzer-Schrehardt U. Exfoliation syndrome. Surv Ophthalmol. 2001;45:265-315.

2. Schlötzer-Schrehardt UM, Koca MR, Naumann GO, Volkholz $H$. Pseudoexfoliation syndrome. Ocular manifestation of a systemic disorder? Arch Ophthalmol. 1992;110:1752-6.

3. Streeten BW, Li ZY, Wallace RN, Eagle RC Jr, Keshgegian AA. Pseudoexfoliative fibrillopathy in visceral organs of a patient with pseudoexfoliation syndrome. Arch Ophthalmol. 1992;110:1757-62.

4. Schumacher S, Schlötzer-Schrehardt U, Martus P, Lang W, Naumann GO. Pseudoexfoliation syndrome and aneurysms of the abdominal aorta. Lancet. 2001;3;357:359-60.

5. Atalar PT, Atalar E, Kilic H, Abbasoglu OE, Ozer N, Aksöyek S, et al. Impaired systemic endothelial function in patients with pseudoexfoliation syndrome. Int Heart J. 2006;47:77-84.

6. Feldman HA, Goldstein I, Hatzichristou DG, Krane RJ, McKinlay JB. Impotence and its medical and psychosocial correlates: results of the Massachusetts Male Aging Study. J Urol. 1994;151:54-61.

7. Grover SA, Lowensteyn I, Kaouache M, Marchand S, Coupal L, DeCarolis E, et al. The prevalence of erectile dysfunction in the primary care setting: importance of risk factors for diabetes and vascular disease. Arch Intern Med. 2006;23;166:213-9. 
8. Yaman 0, Gulpinar 0, Hasan T, Ozdol C, Ertas FS, Ozgenc E. Erectile dysfunction may predict coronary artery disease: relationship between coronary artery calcium scoring and erectile dysfunction severity. Int Urol Nephrol. 2008;40:117-23.

9. Paraskevas KI, Koupidis SA, Mikhailidis DP, Oreopoulos DG. Erectile dysfunction: a warning sign of silent vascular disease. Int Urol Nephrol. 2009;41:909-11.

10. Montorsi F, Briganti A, Salonia A, Rigatti P, Margonato A, Macchi $A$, et al. Erectile dysfunction prevalence, time of onset and association with risk factors in 300 consecutive patients with acute chest pain and angiographically documented coronary artery disease. Eur Urol. 2003;44:360-4; discussion 364-5.

11. Streeten BW, Dark AJ, Wallace RN, Li ZY, Hoepner JA. Pseudoexfoliative fibrillopathy in the skin of patients with ocular pseudoexfoliation. Am $\mathrm{J}$ Ophthalmol. 1990;15;110:490-9.

12. Schlötzer-Schrehardt U, Küchle M, Naumann GO. Electronmicroscopic identification of pseudoexfoliation material in extrabulbar tissue. Arch Ophthalmol. 1991;109:565-70.
13. Siu SC, Lo SK, Wong KW, Ip KM, Wong YS. Prevalence of and risk factors for erectile dysfunction in Hong Kong diabetic patients. Diabet Med. 2001;18:732-8.

14. Fedele D, Bortolotti A, Coscelli C, Santeusanio F, Chatenoud $\mathrm{L}$, Colli $\mathrm{E}$, et al. Erectile dysfunction in type 1 and type 2 diabetics in Italy. On behalf of Gruppo Italiano Studio Deficit Erettile nei Diabetici. Int J Epidemiol. 2000;29:524-31.

15. Bacon CG, Hu FB, Giovannucci E, Glasser DB, Mittleman MA, Rimm EB. Association of type and duration of diabetes with erectile dysfunction in a large cohort of men. Diabetes Care. 2002;25:1458-63

Correspondence address: Mehmet Ilker Gökce, MD

Department of Urology Ankara University School of Medicine Adnan Saygun Caddesi,Altındag, Ankara, Turkey

Fax: +31 2 311-2167

E-mail:migokce@yahoo.com 